\title{
Personality Traits and Readiness for Learning: A Review
}

\author{
Owino-O, Harriet Nyakecho, \\ School of Humanities and Social sciences, Pwani University \\ DOI: 10.29322/IJSRP.10.10.2020.p10615 \\ http://dx.doi.org/10.29322/IJSRP.10.10.2020.p10615
}

\begin{abstract}
The aim of this paper is to identify the relationship between personality traits and readiness for learning based on a review of recent literature. The paper, to a large extent, uses literature to appraise the postulations of James Marcia in the Identity Status Theory, which is an extension of the work of the psychologist Erik Erikson. In applying the identity status theory, this paper attempts to explain how personality traits are extensions of identities at different state of formation. Understanding these traits can be instrumental in helping a learner to commit to learning. The author shows that the knowledge of personality style and identity may help a teacher to determine the best methods for teaching different learners. The paper concludes that people learn and teach differently because they are different. Consequently, teachers should endeavour to understand the potential interpersonal frustrations and curtail unnecessary conflicts by creatively adjusting teaching according to the different personalities of learners.
\end{abstract}

Index Terms- Personality, Traits, Readiness, Learning

\section{INTRODUCTION}

$\mathrm{P}^{\mathrm{e}}$ ersonality traits are key determinants of academic achievement in school. Personality is the unique set of characteristics and qualities that unequivocally defines an individual across situations and contexts. A trait is any aspect of personality that is reasonably characteristic and distinctive. The concept of a personality trait is rooted in common sense and everyday observation. Personologists consider or conceive traits as internal predispositions that are relatively stable over time and across situations. It can also refer to the broad individual differences in socio emotional functioning. Personality traits therefore may be distinguished from other variables that appear to be less socio-emotional and more cognitive in nature such as values, attitudes, worldviews and schemas.

The notion that people could be grouped into different types or categories goes back at least to the time of Hippocrates (about 400 BC), whose ideas were later embellished by Galen (about AD 150). People were thought to be of four groups which were; the choleric (irritable), melancholic (depressed), sanguine (optimistic) and phlegmatic (calm). Each personality type was thought to reflect an excess of one of the bodily fluids. Carl Jung (1993) however argued that people are either introverts or extroverts. According to him, an introvert tends to be alone a lot, behaves as if shy, and prefers solitary activities to social interaction. When confronted with stress, the introverts withdraw into themselves. On the other hand, an extrovert is not shy and prefers to spend time with others. When confronted with stress, they seek a group to talk to.

\section{Personality Traits}

According to McCrae and Costa (2003), personality traits are basically characteristics ascribed to individuals based on their patterns of behaviour, thoughts and emotions. Different models have been postulated to advance discussions of personality traits and their effect on various human endeavours. However, the most commonly used model is the Five-Factor Model (Parks-Leduc, Feldman \& Bardi, 2015). This model categorizes several behavioural and identity characteristics into five groups of traits, namely Openness to experience, Agreeableness, Extraversion, Conscientiousness, and Emotional stability (Parks-Leduc et al., 2015). Openness to experience encompasses such characteristics as curious, intellectual, imaginative, creative, innovative, and flexible (vs. closed-minded, shallow, and simple). On the other hand, Agreeableness is a trait attributed to people who tend to be helpful, good-natured, cooperative, sympathetic, trusting, and forgiving (vs. rude, selfish, hostile, uncooperative, and unkind). Extraversion describes people who are sociable, talkative, optimistic, ambitious, assertive, reward-seeking, outgoing, and energetic (vs. introverted, shy, reserved, quiet, and unadventurous). Conscientiousness defines people who are organized, responsible, dependable, neat, efficient, and achievement-oriented (vs. disorganized, lazy, irresponsible, careless, and sloppy). Lastly, Emotional stability comprises calm, self-confident, stable, resilient, and well-adjusted (vs. neurotic, nervous, insecure, fearful, and anxious).

Personality traits are important for understanding of the environment, or ideas and how individuals engage with others. A wide consensus among researchers for the Five Factor Theory (McCrae and Costa, 1997, 1999, 2003) conjectures that the five structural personality traits or basic tendencies are universal across nationalities and transcend culture (Cattell, 1943; Goldberg, 1993). According to Goldberg (1993), the five factors of personality help to provide a scientific framework for organizing the multitude of differences that are characteristic of human beings everywhere. Consequently, these five dimensions of personality have dominated studies on individual differences (Saksvik \& Hetland, 2009), and have been proven to inform behaviour (Armenakis et al., 1993; Kornør, \& Nordvik, 2004; Shahrazad, Lukman, Murni, et al., 2011; Van Egeren, 2009). It is therefore important to examine how these traits in learners influence their readiness to learn. 


\section{READINESS FOR LEARNING}

Readiness for learning is the capacity to receive, internalize and act on acquired skills. It is a paradoxical concept that implies preparation for something else (learning), yet, as a process, it also requires learning. It is plausible to say readiness for learning is the individual state where one is physically, mentally and emotionally ready to learn. Preparedness to learn is a gimmick, an easy way to rapidly increase the rates of learning contrary to not geared up to learn which diverts attention away and one cannot learn successfully (Prakash, 2012). Hypothetically, it may be difficult for learners to prepare unless they are helped (taught) to prepare to learn. Readiness for learning is important since, as Schindler (2013) argues, even the most optimal conditions for teaching and learning may disfavour certain learners who are not prepared to meet the demands of the learning environment. The unforeseen deception of unpreparedness to learn is shattering as it tends to decrease the efficiency and effectiveness of teaching. One reason, for instance, could be the fact that learners may not have "attained the physical and mental maturity, the foundation of concepts and the language or the social and emotional adjustment necessary for learning at the level which the teacher is attempting" (Schindler, 2013 , p. 301). Therefore, teaching must be appropriate to the readiness level of the learners; otherwise, the goals of teaching will be untenable.

Readiness for learning was initially proposed in relation to early childhood education, with particular concern being to ensure that pre-schoolers are prepared to get in and remain competent in acquiring knowledge within established educational systems. However, it is not merely a construct aimed at ensuring that no child is left behind; it entails a process of capacity building that is subject to many forces, both within and outside the learner's control. According to Heller, Wolfe and Steinberg (2017), contemporary students must cultivate the full range of intellectual, interpersonal, and intrapersonal capacities that have been grouped together under the banner of deeper learning. What role do personality traits play in the process of students' cultivation of these capacities?

Table 1: Identity Statuses and Individual Characteristics

\begin{tabular}{|c|c|}
\hline Identity Status & Characteristics of individuals \\
\hline Identity achievement & $\begin{array}{l}\text { - Solid with important focuses in their lives } \\
\text { - Retain some flexibility, but are not easily swayed by external influences and pressures in } \\
\text { their chosen life directions } \\
\text { - Persevere against obstacles, unless proceeding becomes clearly unrealistic } \\
\text { - Have room for understanding the experiences of others } \\
\text { - Reliable and sources of strength for others }\end{array}$ \\
\hline Moratoriums & $\begin{array}{l}\text { - Struggling to define themselves } \\
\text { - Lively, engaging, conflicted, and sometimes tiring to be around } \\
\text { - May try to draw others into their identity formation project } \\
\text { - Often exquisitely morally sensitive } \\
\text { - Best of outcomes: make self-relevant choices and move on to the firm commitments of } \\
\text { identity achievement } \\
\text { - Worst of outcomes: can become paralyzed in their vacillations }\end{array}$ \\
\hline Foreclosure & $\begin{array}{l}\text { - Appear as strong and self-directed as achievements } \\
\text { - There is a brittleness, and, hence, underlying fragility, to their position } \\
\text { - Have difficulty considering alternatives seriously; they thus maintain their stances } \\
\text { defensively and either deny or distort disconfirming information } \\
\text { - Seek conforming positions which helps them to find self and familial affirmations }\end{array}$ \\
\hline
\end{tabular}

This publication is licensed under Creative Commons Attribution CC BY.

http://dx.doi.org/10.29322/IJSRP.10.10.2020.p10615

Www.ijsrp.org 


\begin{tabular}{|l|l|}
\hline Identity diffusions & - Have a weak or non-existent exploratory period and an inability to make definite \\
& commitments \\
& - Can be whatever current influences shape them to be \\
& - At their best, they can appear extremely flexible, charming, and infinitely adaptable \\
At their worst, diffusions are lost and isolated, beset by feelings of emptiness and \\
meaninglessness
\end{tabular}

Source: Adapted from Kroger and Marcia (2011)

In applying the identity status theory, this paper attempts to explain how personality traits are extensions of identities at different state of formation. Understanding these traits can be instrumental in helping a learner to commit to learning. According to Luyckx, Teppers, Klimstra and Rassart (2014), personality have been known to be some of the key contributors to variations in identity development among people. Similarly, Vancea (2014) observes that "The psychic maturity level reached by an individual depends on the way in which he succeeds in accepting and going through identity crises, eventually assuming a clear, precise and authentic personal identity" (p. 5-6). However, these authors lament that there is a research gap on the relationship between personality traits and current identity models. In contribution to filling this gap and address the paucity of studies, this paper examines the relationship between personality traits and readiness for learning, which is conceptualized as part of an identity commitment.

\section{PERSONALITy TRAITS AND LEARNING}

In their 2011 book titled How to Teach Now: Five Keys to Personalized Learning in the Classroom, Powell and KusumaPowell urges teachers to understand their students well. Among the benefits they enumerate for knowing students is the teachers' ability to gauge fully every learner's capacity and readiness for learning. Such knowledge will then enable the teachers to create a psychologically safe environment for every learner. Knowing a student's readiness level will also enable the teacher to define strategies for accessing the curriculum to enhance participation. According to Powell and Kusuma-Powell, contemporary teachers must demonstrate a heightened emotional intelligence in the classroom.

Komarraju, Karau, Scmeck and Avdic (2011) have studied the big five personality traits, learning styles and academic achievement. They found that conscientiousness and agreeableness had a positive relationship with key learning styles, namely synthesis analysis, methodical study, fact retention and elaborate processing. These findings suggest that these personality traits are likely to be ready for deep learning styles. From the instant study, extraversion and openness also registered fair performance with elaborate processing learning styles. On the other hand, Komarraju et al. (2011) found that neuroticism was negatively associated with all these learning styles. This means that neurotics are not ready to learn using these deep learning approaches and teachers may need to alter their goals and styles to meet the needs of such learners. The authors conclude that students who are intellectually curious are more ready to learn than those who are emotionally unstable.

In a study of personality traits, learning and academic achievements, Jensen (2015) observes that openness is marked by a student's desire to know more. Accordingly, such students have both the intrinsic drive to seek out knowledge and allow themselves to be extrinsically stimulated to learn. The implication is that openness as a personality trait allows for greater readiness for learning. Jensen further notes that openness is positively linked to deep learning and negatively correlated to surface learning. Conscientiousness also had a significant, albeit less strong, association with deep and achieving learning. He however reports a weak association between deep learning and extraversion and agreeableness. Lastly, students who lack emotional stability (neurotics) exhibit a higher affinity for surface as opposed to deep learning.

Corker, Oswald and Donnellan (2012) observe that of the big five personality traits, conscientiousness presents a strong predictor of preparedness for high academic achievement. A key factor in conscientiousness that researchers single out as the greatest driver for the desire to learn is self-efficacy (Cupani \& Pautassi, 2013). Nonetheless, Corker et al. note that learners with this type of trait need purposeful guidance to stay committed to their academic pursuits. The reason is that these learners tend to gravitate towards laziness and loss of focus. They also tend to be negligent and early quitters.

On the other hand, Steele-Johnson and Leas (2013) have found that openness has an indirect influence on student's readiness for learning and ultimately on their academic performance. This indirect effect stems from the fact that learners with this type of trait tend to easily slip into conventions so as to gain social acceptance, instead of seeking to be creative and independent of mind. To such learners, subscribing to conservative views may be easier and a way of showing that they accommodate other people's ideas. According to Steele-Johnson and Leas, however, openness is a stronger predictor of learning at the lower levels of education compared to conscientiousness, which is strongest at the higher levels of learning. This may be explained by the fact at a younger stage, most open children are honest and down-to-earth.

Studies that explore the influence of emotional stability on learning mostly examine the impact of neuroticism on students' performance. For instance, Richardson, Abraham and Bond (2012) predict that neuroticism may render a learner completely dysfunctional in the classroom setting due to its associated factors. These factors include stress, unhealthy behavior patterns and low self-esteem. However, Beckmann, Beckmann and Birney (2013) argue that neuroticism can even drive students to concentrate more on trying to resolve their internal issues by acquiring skills. Therefore, neuroticism does not always imply a student is not ready to participate in a learning environment. It may simply imply the need for the teacher to make certain adjustments to help that student tap into their internal motivators for knowledgeseeking actions. 
Richardson et al. (2012) also observe that learners with agreeableness may desire collaborative learning set-ups in order to perform. These authors also paint a similar scenario for students with extraversion personality traits. According to them, extraversion promotes outward looking behaviour which can distract a learner from their academic work. Therefore, they caution that learners with these two trait types tend to lose focus easily. As such, the best approach to helping such learners is to provide social learning groups. Such groups will provide them with a place of affirmation and social identity.

Based on the literature review, Table 2 below provides a summary of the potential issues that teachers may need to address across the personality trait categories in relation to students' readiness for learning.

Table 2: Personality Traits, Student Characteristics and Readiness for Learning

\begin{tabular}{|c|c|}
\hline Personality Trait & Low score characteristics of students that could impair with readiness for learning \\
\hline Openness & $\begin{array}{l}\text { Down-to-earth: Can be naïve and gullible } \\
\text { Uncreative and conventional/conservative: Does not interrogate existing ideas and } \\
\text { assumptions. } \\
\text { Prefers routine: Reluctant to change or take up new subjects. } \\
\text { Uncurious: Does not show 'hunger' for learning. }\end{array}$ \\
\hline Agreeableness & $\begin{array}{l}\text { Ruthless: Can be unconcerned with fellow learners } \\
\text { Suspicious: Does not trust the teacher or colleagues. } \\
\text { Stingy: Does not collaborate with other learners } \\
\text { Antagonistic, critical, irritable: Tendency to be the notorious noise-maker in class. } \\
\text { Easily distracted: Lacks focus/short attention span. }\end{array}$ \\
\hline Extra & $\begin{array}{l}\text { Reserved/quiet: Would rather not ask questions, even when they desire to. } \\
\text { Loner: Hates group works. } \\
\text { Sober, passive, unfeeling: Lost in their own world/day-dreaming in the classroom. }\end{array}$ \\
\hline Conscie & $\begin{array}{l}\text { Negligent: Loses marks for minor mistakes/lack of attention to detail } \\
\text { Lazy: Loves last-minute actions } \\
\text { Disorganized: Finds it hard to revise from poorly constructed notes } \\
\text { Late: Misses out on key introductory topics } \\
\text { Aimless: Always disoriented during learning } \\
\text { Quitting: Gives up when things get tough }\end{array}$ \\
\hline Emotional stability & $\begin{array}{l}\text { Neurotic: Always afraid to fail leading to inaction or hyperactivity. } \\
\text { Short-tempered: Reactive to situations } \\
\text { Self-satisfied, comfortable: Does not see the need to seek more knowledge or } \\
\text { understanding of issues } \\
\text { Unemotional, hardy: Lacks emotional intelligence }\end{array}$ \\
\hline
\end{tabular}

Source: Adapted from Feist and Feist (2009) 


\section{JAMES MARCIA'S IDENTITY STATUS: IMPLICATIONS ON READINESS FOR LEARNING}

Expanding in the foundational works of Erik Erikson, James Marcia (1966) proposes two criteria that are necessary for a mature identity achievement. These are crisis and commitment. Crisis refers to the struggle or emotional turmoil a person goes through in making choices; commitment on the other hand, describes the amount of personal investment an individual exhibits in making a choice. These are important to identity because without some sort of crisis or deep soul searching in making important life decisions one has to question whether a decision is really one's own. Similarly, without a strong commitment to life choices, there is the possibility one has not weighed the full rewards and costs of these choices and will most likely abandon them as soon as soon as opposition or difficult circumstances arise.

When a teacher reflects on this, it is important to recognize the fact that students will be ready to learn only when they make a conscious decision to actively take part in the learning process. In addition to this without commitment, effective learning cannot take place. In summary, one's self-image plays a significant role in forming ones sense of identify and having a healthy individuality is a premise for creating an industrious leaning environment. To properly assess a student's readiness to learn, teachers need to look at key indicators of personality and identity. These include temperament, show of personal abilities or unique talents, the student's cultural and family background and personal identity.

\section{Temperament}

Temperament describes how a person feels and acts. Bould, Joinson, Sterne and Araya (2012) describe temperament using concepts such as emotionally, activity and sociability. Emotionality is the tendency show distress and the tendency to become upset easily and intensely. This distress stems from fear and anger. On the other hand, activity includes tempo, vigour and endurance while sociability refers to the preference one has to be with others as opposed to being alone (Bould et al., 2012). Social rewards that stem from one's sociability include the presence of others sharing an activity, attention, responsibility, and initiation. The combination of these three aspects of temperament yields very diverse personality types. Just as everyone has unique talents individuals also have unique temperaments.

Dougherty (2016) posits that over $60 \%$ of children in the world fall into one of three temperament categories, namely: easy or flexible; difficult, active or feisty, and slow to warm up or cautious. The first group represents a calm and happy personality, identified by how a child loves to sleep and eat well. The second group comprises children who are fussy and easily distracted, marked by short attention span, irregular sleeping and eating habits and irrational fear or neuroticism. The last category is composed of children who are withdrawn, but tend to react sharply, mostly negatively, to new experiences. These children need gradual exposure to new learning experiences. Therefore, it is important to examine how a learner's temperament drives them towards or away from the desire to pursue knowledge. Teachers should strive to recognize the various temperaments represented in a classroom setting and the different learning styles that every temperament may need.

\section{Abilities}

Every person is endowed with certain abilities, which gradually develop through maturation and learning. The ability to learn, engage in abstract ideation or reasoning and solve problems is referred to as intelligence (Legg \& Hutter, 2007). A special ability such as a talent for music or mechanical things is called aptitude. Intelligence influences personality by providing a student with means of recognition, an outstanding quality. The bright child achieves rewards from parents and teachers for his or her accomplishments. Abilities also provide a motivation to learn as a student with, say, a special talent desires to exercise and perfect it. This explains why innate abilities are useful tools for assessing a student's readiness for learning. Having these abilities is not synonymous with being ready to learn; in fact learners who feel able may not see the need to seek more knowledge or training. Therefore, they may need motivation to step out of their state of contentment and to remain curious about abilities they may be lacking.

\section{Culture and Family}

Whether or not a child was raised in the rural and less developed regions of Africa or the sophisticated cities of the United States, cultural and family circumstances do have an impact on their readiness to learn. Culture determines the experiences a person has, the frustrations and adjustments he must deal with against the standards of conduct required of him within the learning environment (Futterman, 2015). Each culture has its own distinctive value, morals, and ways of behaving. It dictates the rules for child training and relationships within a family. According to Futterman, culture and family imbue in a child a worldview that may restrict or expand their ability to learn. Parents' behaviour and perceptions of school and schooling could also promote or undermine a child's readiness to learn. For instance, parents who perceive teachers as experts may not exert additional effort to prepare their children for learning.

\section{Identity}

"Who am I?" is a question constantly confronted from childhood through adolescence and onto adulthood. The essence of personality development is to create identity, distinct from those of others (friends, peers, parents, relatives, church members, teachers, etc.). A sense of identity is not innate or inborn. When a child goes to school, they identify themselves as learners. However, to what extent does this self-definition result in actual transition in the mind of the child? However, a child within a school context is at the same time a person with several personalities, including sexual orientation, religious beliefs, gender, race or ethnicity, socio-economic class, physical or mental abilities, political background, etc. (DiPietro, 2007). It is important when assessing a child's readiness for learning that teachers pay attention to all the identities that could distract a child from learning.

\section{CONCLUSION AND PRACTICAL IMPLICATIONS}

The knowledge of personality style and identity may help a teacher to determine the best methods for teaching different learners. Some students pass a more "take charge" manner 
("tellers") while others prefer to come at problems by raising tough questions ("askers"). Therefore, equipped with the knowledge of the different personality types, the teacher will develop a suitable model to hold the attention of every learner. Teachers are encouraged to provide a balanced style of teaching so that all students are catered for and motivated to learn. The teacher should endeavour to understand the potential interpersonal frustrations and curtail unnecessary conflicts by creatively adjusting teaching according to the different personalities of learners.

Personality types also affect learners' self-concept, which is a key determiner of learning motivation. Teachers will often find it difficult to motivate reluctant learners unless they identify the root causes of their (learners') self-concepts. Self-concept comprises all that one knows or thinks they know about themselves. It includes one's evaluation of self, how competent and effective they consider themselves to be, what they expect of themselves, and one's identity. Therefore, a proper understanding of how self-concept affects learning orientation can help teachers to motivate all types of learners effectively. Ultimately, as highlighted in this paper, temperament and personality type theories show that people learn and teach differently because they are different. Therefore, learning about temperament and personality types can help teachers to appreciate themselves as teachers; to better understand their students, and identify as well as deal effectively with theirs and their learners' strengths and weaknesses.

\section{REFERENCES}

[1] Armenakis, A. A., \& Fredenberger, W. B. (1997). Organizational change readiness practices of business turnaround change agents. Knowledge and Process Management, 4(3), 143-152.

[2] Bould, H., Joinson, C., Sterne, J., \& Araya, R. (2012). The Emotionality Activity Sociability Temperament Survey: Factor Analysis and Temporal Stability in a Longitudinal Cohort. Personality and Individual Differences, 54(5), 628-633.

[3] Cattell, R. B. (1943). The description of personality: Basic traits resolved into clusters. The journal of abnormal and social psychology, 38(4), 476.

[4] Corker, K. S., Oswald, F. L., \& Donnellan, M. B. (2012). Conscientiousness in the Classroom: A Process Explanation. Journal of Personality, 80, 9951027.

[5] Cupani, M., \& Pautassi, R. M. (2013). Predictive Contribution of Personality Traits in a Sociocognitive Model of Academic Performance in Mathematics. Journal of Career Assessment, 21, 395-413

[6] Dougherty, N. (2016, May 17). Approaches to Learning and Temperament. Early Learning Success. Retrieved May 13, 2018 from http://earlylearningsuccess.net/approaches-learning-temperament/

[7] Feist, J., \& Feist, G. J. (2009). Theories of Personality. Singapore: McGrawHill.

[8] Flores-Crespo, P. (2007). Situating education in the human capabilities approach. In Amartya Sen's capability approach and social justice in education (pp. 45-65). Palgrave Macmillan, New York.

[9] Futterman, L. (2015, September 29). Beyond the Classroom: The Impact of Culture on the Classroom. Miami Herald. Retrieved May 14, 2018 from http://www.miamiherald.com/news/local/community/miamidade/community-voices/article36727782.htm
[10] Goldberg, L. R. (1993). The structure of phenotypic personality traits. American psychologist, 48(1), 26.

[11] Heller, R., Wolfe, R. E., \& Steinberg, A. (2017). Rethinking Readiness: Deeper Learning for College, Work, and Life. Havard: Harvard Education Press.

[12] Jensen, M. (2015). Personality Traits, Learning and Academic Achievements. Journal of Education and Learning, 4(4), 91-118.

[13] Komarraju, M., Karau, S. J., Scmeck, R. R., \& Avdic, A. (2011). The Big Five Personality Traits, Learning Styles, and Academic Achievement. Personality and Individual Differences, 51(4), 472-477.

[14] Kornør, H., \& Nordvik, H. (2004). Personality traits in leadership behavior Scandinavian Journal of Psychology, 45(1), 49-54.

[15] Kroger, J., \& Marcia, J. E. (2011). The Identity Statuses: Origins, Meanings, and Interpretations. In S. J. Schwartz, K. Luyckx, \& V. L. Vignoles (Eds.), Handbook of Identity Theory and Research (31-53). New York: SpringerVerlag.

[16] Legg, S., \& Hutter, M. (2007). A Collection of Definitions of Intelligence. Technical Report. IDSIA.

[17] Luyckx, K., Teppers, E., Klimstra, T. A., \& Rassart, J. (2014). Identity Processes and Personality Traits and Types in Adolescence: Directionality of Effects and Developmental Trajectories. Developmental Psychology, 50(8), 2144-2153

[18] Marcia, J. E. (1993). The ego identity status approach to ego identity. In Ego identity (pp. 3-21). Springer, New York, NY.

[19] McCrae, R. R., \& Costa, P. T., Jr. (2003). Personality in Adulthood: A FiveFactor Theory Perspective. New York, NY: Guilford Press.

[20] Parks-Leduc, L., Feldman, G., \& Bardi, A. (2015). Personality Traits and Personal Values: A Meta-Analysis. Personality and Social Psychology Review, 19(1) 3-29.

[21] Powell, W., \& Kusuma-Powell, O. (2011). How to Teach Now: Five Keys to Personalized Learning in the Classroom. Association for Supervision \& Curriculum Development.

[22] Prakash, L. S., \& Saini, D. K. (2012, July). E-assessment for e-learning. In 2012 IEEE International Conference on Engineering Education: Innovative Practices and Future Trends (AICERA) (pp. 1-6). IEEE.

[23] Richardson, M., Abraham, C., \& Bond, R. (2012). Psychological Correlates of University Students' Academic Performance: A Systematic Review and Meta-Analysis. Psychological Bulletin, 138, 353-387.

[24] Saksvik, I. B., \& Hetland, H. (2009). Exploring dispositional resistance to change. Journal of Leadership \& Organizational Studies, 16(2), 175-183.

[25] Schindler, A. W. (2013). Readiness for Learning. Childhood Education [Online], 24(7), 301-304.

[26] Shahrazad, W. W., Lukman, Z. M., Murni, A. R., Zainah, A. Z., Fauziah, I., \& Arifin, Z. (2011). Personality traits as predictors towards readiness to change among female drug addicts. American Journal of Applied Sciences, $8(2), 134$.

[27] Steele-Johnson, D., \& Leas, K. (2013). Importance of race, Gender, and Personality in Predicting Academic Performance. Journal of Applied Social Psychology, 43, 1736-1744.

[28] Vancea, F. (2014). Personality, Identity and Psychic Maturity. International Conference of Scientific Paper, AFASES, Brasov, 22-24 May 2014.

[29] Van Egeren, L. F. (2009). A cybernetic model of global personality traits. Personality and Social Psychology Review, 13(2), 92-108.

\section{AUTHORS}

First Author - Owino-O, School of Humanities and Social sciences, Pwani University

Second Author - Harriet Nyakecho, School of Humanities and Social sciences, Pwani University, Email:

hariet.scott@gmail.com 
